\title{
Effects of anthocyanidin derivative (HK-008) on relaxation in rat perfused mesenterial bed
}

\author{
Katsuo KAMATA ${ }^{1}$, Ayako MAKINO ${ }^{1}$, Noriyasu KANIE ${ }^{1}$, Shu-ichi ODA ${ }^{1}$, \\ Takayuki MATSUMOTO ${ }^{1}$, Tsuneo KoBAYASHI ${ }^{1}$, Toyohiko KIKUCHI ${ }^{2}$, \\ Masato NISHIMURA ${ }^{2}$ and Toshio HONDA ${ }^{2}$ \\ ${ }^{1}$ Department of Physiology and Morphology, Institute of Medicinal Chemistry, \\ ${ }^{2}$ Faculty of Pharmaceutical Sciences, Hoshi University, Ebara 2-4-41, Shinagawa-ku, \\ Tokyo 142-8501, Japan
}

Received May 18, 2006; Accepted June 2, 2006

\begin{abstract}
Anthocyanins, which are responsible for a variety of bright colors (including red, blue, and purple) in fruits, vegetables, and flowers, are consumed as dietary polyphenols. Anthocyanin-containing fruits are thought to decrease coronary heart disease and are used in anti-diabetic preparations. Diabetes is associated with a variety of cardiovascular complications that may be mediated by endothelial dysfunction, and so this study was designed mainly to characterize the influence of a synthesized anthocyanidin derivative (HK-008) over acetylcholine (ACh)-induced relaxation in mesenteric arterial beds isolated from rats. In a glucose-tolerance test in intact rats, HK-008 $(30 \mathrm{mg} / \mathrm{kg})$ reduced the glucose level as effectively as the same dose of glibenclamide. The aortic relaxation induced by pinacidil (an ATP-sensitive potassium channel opener) was greatly inhibited by glibenclamide $(10 \mu \mathrm{M})$, and also significantly inhibited by HK-008 $(10 \mu \mathrm{M})$. Interestingly, the ACh-induced relaxation in the perfused, preconstricted mesenteric arterial bed was significantly enhanced by HK-008 $(10 \mu \mathrm{M})$, and this enhancement was significantly attenuated by indomethacin $(10 \mu \mathrm{M})$. The ACh-induced mesenteric relaxation was impaired by an increase in oxidative stress, viz. superoxide-generating treatment [xanthine oxidase $(\mathrm{XO} ; 0.1 \mathrm{U} / \mathrm{ml})$ plus hypoxanthine $(\mathrm{HX} ; 10 \mu \mathrm{M})$ ]. However, this impairment was strongly suppressed by HK-008 $(10 \mu \mathrm{M})$. These results suggest that HK-008 increases endothelium-induced relaxation by suppressing oxidative stress or modulating prostanoids signaling. This compound may therefore be useful against certain cardiovascular disorders.
\end{abstract}

Key words: anthocyanidin, endothelium-dependent relaxation, glibenclamide, mesenteric artery, rat

Correspondence to: Prof. Katsuo Kamata, Department of Physiology and Morphology, Institute of Medicinal Chemistry, Hoshi University, Shinagawa-ku, Tokyo 142-8501, Japan Phone: +81-3-5498-5856 Fax: +81-3-5498-5856 e-mail: kamata@hoshi.ac.jp 


\section{Introduction}

Numerous epidemiological studies have indicated that the insulin resistance and hyperinsulinemia associated with type 2 diabetes make important contributions to the development of hypertension and cardiovascular disorders, and impaired endotheliumdependent vasodilation has been described in humans and in animal models of this disease (Pieper, 1998; Eckel et al., 2002; Kobayashi et al., 2004b, 2005b; Matsumoto et al., 2004d). Moreover, the early loss of insulin secretion appears to be a critical event in the deterioration in glucose tolerance that occurs during the development of type 2 diabetes.

Type 2 diabetes, which is becoming more prevalent, is caused by the inability of $\beta$-cells to secrete sufficient insulin to overcome the insulin-resistance that develops as a consequence of certain genetic and environmental factors (Henquin, 2000). Insulin-resistance is a disorder in which insulin inadequately stimulates glucose transport in skeletal muscle and fat, and inadequately suppresses hepatic glucose production. The mechanisms that prevent the $\beta$-cell from secreting sufficient insulin to overcome peripheral insulin-resistance remain to be established. Use of oral hypoglycemic agents that directly stimulate insulin release from $\beta$-cells [e.g., sulfonylurea (SU)-based drugs], however, has shown that in type 2 diabetic patients, insulin secretion from the islets can be elevated sufficiently to overcome peripheral insulinresistance and the normalize the blood glucose level. One disadvantage of this use of SU-based drugs is that it fails to control normal blood glucose levels (Pfeiffer, 2003). These drugs also adversely affect the ability of $\beta$-cells to secrete insulin, and they can cause weight gain (Pfeiffer, 2003). Hence, a useful role could be performed by dietary constituents with the ability to regulate blood glucose levels or induce insulin production by pancreatic $\beta$-cells.

The consumption of a diet low in fat and rich in antioxidants reduces the risks of developing obesity and insulin-resistance (Blakely et al., 2003). Anthocyanins, which are secondary plant metabolites responsible for the blue, purple, and red colors in many plant tissues, occur primarily as the glycosides of their respective anthocyanidin chromophores (Strack and Wray, 1993). Like other flavonoids, anthocyanins and anthocyanidins (the aglycone form) possess antioxidant properties and are present in various foods and beverages (Wang et al., 1997). Consumption of anthocyanins in associated with a reduced risk of several degenerative diseases, such as atherosclerosis, cardiovascular diseases, cancer, and diabetes (Jayaprakasam et al., 2004). These compounds are well-known free-radical scavengers and are potential chemopreventive agents (Duthie et al., 2000). For example, the serum antioxidant capacity is increased by the consumption of strawberries, cherries, and red wine (Van Velden et al., 2002; Kang et al., 2003). Further, a recent study demonstrated that one anthocyanin, cyaniding 3glusoside, reduced high fat diet-induced obesity in mice (Tsuda et al., 2003). The natural colorants present in food tend to be attractive to consumers because of their safety and because of their nutritional and therapeutic value (Espin et al., 2000). Because anthocyanins are so widely consumed, any additional biological activities of these compounds are of great interest.

In this study, we first compared the potency of a synthesized anthocyanidin-derivative (HK008) with that of glibenclamide at antagonizing the vasodilation elicited by pinacidil, an ATPsensitive potassium $\left(\mathrm{K}_{\mathrm{ATP}}\right)$-channel opener, in the rat aorta. We then evaluated and analyzed the 
effects of HK-008 on the acetylcholine (ACh)-induced endothelium-dependent relaxation in the rat perfused mesenteric arterial bed.

\section{Methods}

\section{General}

The experimental design was approved by the Hoshi University Animal Care and Use Committee, and all studies were conducted in accordance with "Guide for the Care and Use of Laboratory Animals" published by the US National Institute of Health, and "Guide for the Care and Use of Laboratory Animals" adopted by the Committee on the Care and Use of Laboratory Animals of Hoshi University (accredited by the Ministry of Education, Culture, Sports, Science, and Technology, Japan).

\section{Materials}

(-) Noradrenaline hydrochloride (NA), methoxamine hydrochloride, sodium nitroprusside (SNP), indomethacin, pinacidil, hypoxanthine (HX), and xanthine oxidase (XO) were purchased from Sigma Chemical Co. (St. Louis, MO, U.S.A.). Acetylcholine chloride (ACh) was from Daiichi Pharmaceuticals (Tokyo, Japan). The present anthocyanidin derivative [namely, 7,8dihydroxy-2-(4-hydroxyphenyl)-1-benzopyrylium chloride (HK-008)] (Fig. 1) was developed in our laboratories. All drugs were dissolved in saline, except glibenclamide, which was dissolved in dimethyl sulfoxide (DMSO). All concentrations are expressed as the final molar concentration of the base in the organ bath.

\section{Intraperitoneal glucose tolerance test}

Male Wistar rats (18-20 weeks old) were fasted overnight and then anesthetized with pentobarbital (65 mg/kg i.p.). After collection of an unchallenged sample (time 0 ), a solution of glucose $(1.0 \mathrm{~g} / \mathrm{kg}$ body weight) was administered into the peritoneal cavity. Blood samples were collected from the tail at 30 and $60 \mathrm{~min}$ for the determination of glucose. To investigate the effects of glibenclamide $(30 \mathrm{mg} / \mathrm{kg})$ and HK-008 $(30 \mathrm{mg} / \mathrm{kg})$ on the glucose level, these drugs were orally administered 30 min before the glucose injection.

\section{Preparation of aortic strips}

Male Wistar rats, 18-20 weeks old, were anesthetized with diethyl ether and euthanized by decapitation. A thoracic aorta strip was prepared using a method previously described by us (Kobayashi et al., 2000; Kanie et al., 2003; Kobayashi et al., 2004a; Matsumoto et al., 2004b, 2005). Briefly, a section of the aorta from between the aortic arch and the diaphragm was removed and placed in oxygenated, modified Krebs-Henseleit solution (KHS). This solution consisted of (in mM) $118.0 \mathrm{NaCl}, 4.7 \mathrm{KCl}, 25.0 \mathrm{NaHCO}_{3}, 1.8 \mathrm{CaCl}_{2}, 1.2 \mathrm{NaH}_{2} \mathrm{PO}_{4}, 1.2 \mathrm{MgSO}_{4}$, and 11.0 dextrose. The aorta was cleaned of loosely adhering fat and connective tissue, then cut into helical strips $3 \mathrm{~mm}$ in width and $20 \mathrm{~mm}$ in length. Each strip was placed in a well-oxygenated $\left(95 \% \mathrm{O}_{2}, 5 \% \mathrm{CO}_{2}\right)$ bath of $10 \mathrm{ml} \mathrm{KHS}$ at $37^{\circ} \mathrm{C}$, with one end connected to a tissue holder and the other to a force-displacement transducer (Nihon Kohden, TB-611T). The tissue was 


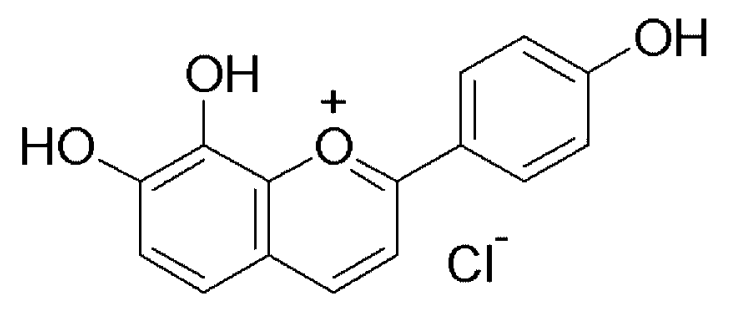

\section{HK-008}

Fig. 1. Chemical structure of HK-008.

equilibrated for 60 min under a resting tension of $1.0 \mathrm{~g}$, which was found to be optimal for inducing maximal contractions in preliminary experiments. For the relaxation studies, the aortic strips, which were weighed at the end of each experiment, were precontracted with an equieffective concentration of NA $\left(5 \times 10^{-8}\right.$ to $\left.3 \times 10^{-7} \mathrm{M}\right)$. When the NA-induced contraction had reached a plateau level, pinacidil $\left(10^{-8}\right.$ to $\left.10^{-4} \mathrm{M}\right)$ was added in a cumulative manner. After the addition of sufficient aliquots of one of the above agents to produce the chosen concentration, a plateau response was allowed to develop before the addition of the next dose of the same agent. To investigate the effects of $10^{-5} \mathrm{M}$ glibenclamide and $10^{-5} \mathrm{M}$ HK-008 on the relaxation responses, the strip was incubated for $30 \mathrm{~min}$ in the appropriate medium before the cumulative addition of the drug. These agents did not influence the NA-induced precontraction in our preparations.

\section{Preparation of the perfused mesenteric arterial bed}

Male Wistar rats (18-20 weeks old) were anaesthetized with ether and given an intravenous injection of 1,000 units $\mathrm{kg}^{-1}$ of heparin. Then, the mesenteric arterial bed was rapidly dissected out and placed in KHS. The mesenteric artery and vein were tied off near the caecum, and the remaining intestine was separated from the arterial bed along the intestinal wall. The mesenteric arterial bed was then perfused using a method previously described by us (Kamata and Makino, 1997; Makino and Kamata, 1998, 2002; Makino et al., 2000; Matsumoto et al., $2004 \mathrm{a}, \mathrm{b})$. Briefly, warm $\left(37^{\circ} \mathrm{C}\right)$, oxygenated $\left(95 \% \mathrm{O}_{2}, 5 \% \mathrm{CO}_{2}\right) \mathrm{KHS}$ was pumped into the mesenteric arterial bed, using a peristaltic pump operating at a rate of $5 \mathrm{ml} \mathrm{min} \mathrm{m}^{-1}$, through a cannula inserted into the superior mesenteric artery. Vascular responses were detected as changes in perfusion pressure; this was monitored continuously by way of a pressure transducer (Nihon Kohden, Model AP2001, Tokyo, Japan) and recorded on a pen recorder. For the relaxation study, after a 60 -min equilibration period the perfusion circuit was transformed into a closed system by collecting the perfusate in a second bath and from thence recirculating it through the mesenteric arterial bed. The total volume of the closed system was $50 \mathrm{ml}$, and agents were administered via the bath. In some preliminary experiments, the mesenteric arterial bed preparation was constricted by perfusion with a solution containing $4 \times 10^{-6}$ to $3 \times$ $10^{-5} \mathrm{M}$ methoxamine, which resulted in an increase in perfusion pressure of approximately 105- 


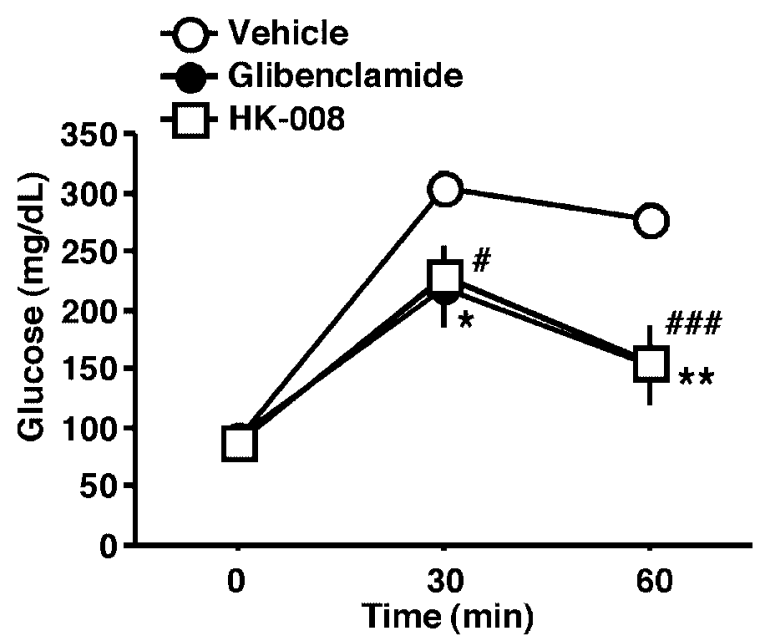

Fig. 2. Effects of glibenclamide and HK-008 on plasma glucose levels during glucose tolerance test in rats. Details are given in Methods. Each data-point represents the mean \pm S.E.M. from 4 (glibenclamide) or 5 (vehicle or HK-008) experiments; the S.E.M. is included only when it exceeds the dimension of the symbol used.

$120 \mathrm{mmHg}$. It was then maximally relaxed with a perfusion solution containing $10^{-6} \mathrm{M} \mathrm{ACh}$, a response that confirmed the integrity of the endothelium in our preparation. In order to standardize the vasodilator responses obtained with $\mathrm{ACh}$, such responses were expressed as a percentage of that induced by papaverine $\left(10^{-4} \mathrm{M}\right)$ in one and the same preparation. In each preparation, once the methoxamine-induced contraction had reached a plateau, relaxation responses to a given agonist were elicited in a cumulative manner. To investigate the influence of HK-008 $\left(10^{-5} \mathrm{M}\right)$, indomethacin $\left(10^{-5} \mathrm{M}\right)$, and xanthine oxidase (XO; $\left.0.1 \mathrm{U} / \mathrm{ml}\right) /$ hypoxanthine (HX; $10 \mu \mathrm{M}$ ) on the ACh-induced relaxation, the mesenteric arterial bed was incubated in the appropriate solution for $30 \mathrm{~min}$ before the addition of methoxamine. These agents did not influence the methoxamine-induced precontraction in our preparations.

\section{Statistical analysis}

Data are expressed as the mean \pm S.E.M. When appropriate, statistical differences were assessed by means of Dunnett's test for multiple comparisons after a one-way analysis of variance, a probability level of $P<0.05$ being regarded as significant. Statistical comparisons between concentration-response curves were made by means of a two-way ANOVA, with Bonferroni's correction for multiple comparisons being performed post hoc $(P<0.05$ again being considered significant).

\section{Results}

\section{Intraperitoneal glucose tolerance test}

In an intraperitoneal glucose tolerance test in rats (Fig. 2), administration of HK-008 at a dose of $30 \mathrm{mg} / \mathrm{kg}$ p.o. significantly lowered the plasma glucose level. The reference drug 


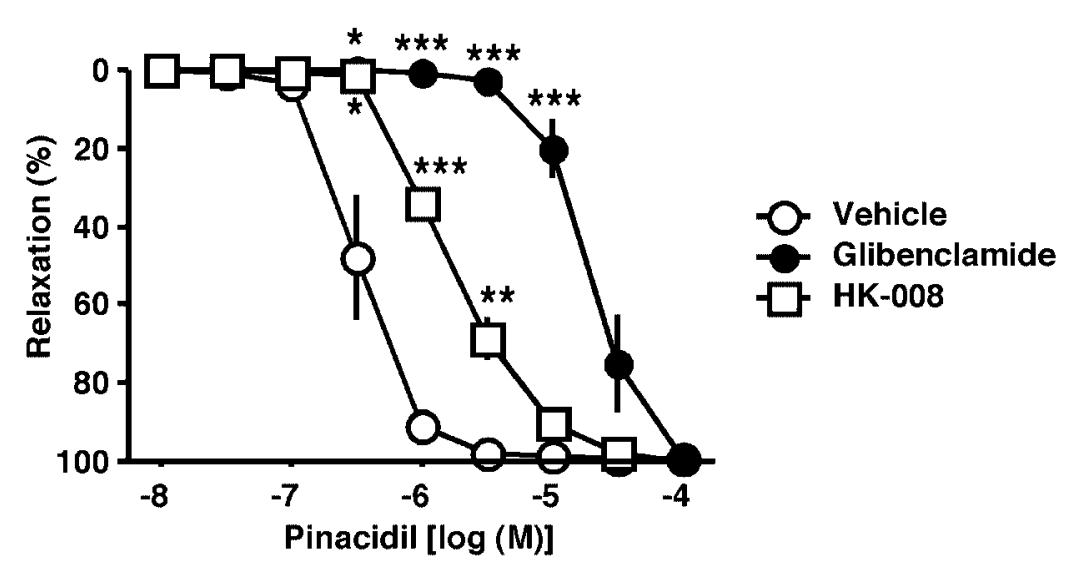

Fig. 3. Effects of glibenclamide and HK-008 on the relaxations evoked by pinacidil $\left(10^{-8}-10^{-4}\right.$ $\mathrm{M})$ in aortic strips from rats. In each experiment, glibenclamide $(10 \mu \mathrm{M})$ or HK-008 $(10 \mu \mathrm{M})$ was applied $30 \mathrm{~min}$ before noradrenaline application and was present thereafter. Details are given in Methods. Each data-point represents the mean \pm S.E.M. from 4 (glibenclamide) or 5 (vehicle or HK-008); the S.E.M. is included only when it exceeds the dimension of the symbol used. ${ }^{\star} P<0.05,{ }^{\star \star} P<0.01,{ }^{* \star}{ }^{\star} P<0.001$ vs. vehicle-treated group.

(glibenclamide; $30 \mathrm{mg} / \mathrm{kg}$ p.o.) had a significant hypoglycemic effect of similar magnitude.

Effects of HK-008 and glibenclamide on pinacidil-induced relaxation in aortic strips

To determine whether our synthesized compound really did act as a $\mathrm{K}_{\mathrm{ATP}}$ channel inhibitor, we performed a series of experiments in which pinacidil $\left(10^{-8}\right.$ to $10^{-4} \mathrm{M}$, a $\mathrm{K}_{\mathrm{ATP}}$ channel opener) was added cumulatively to aortic strips precontracted by NA $\left(5 \times 10^{-8}\right.$ to $\left.3 \times 10^{-7} \mathrm{M}\right)$ in the

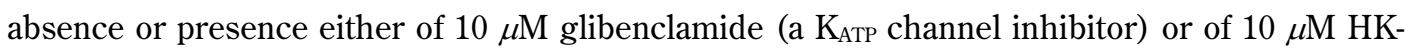
008. The results are summarized in Fig. 3. Pinacidil caused a concentration-dependent relaxation [vehicle, $\mathrm{EC}_{50}: 0.38 \pm 0.08 \mu \mathrm{M}(\mathrm{n}=5)$ ]. Glibenclamide $\left(10^{-5} \mathrm{M}\right)$ shifted this doseresponse curve to the right $\left[\mathrm{EC}_{50}: 21.6 \pm 5.8 \mu \mathrm{M}(\mathrm{n}=4, P<0.01 v\right.$ s. vehicle) $]$, as did HK-008 (10-5 M) $\left[\mathrm{EC}_{50}: 2.1 \pm 0.4 \mu \mathrm{M}(\mathrm{n}=5, P<0.01\right.$ vs. vehicle) $]$.

Effects of HK-008 on endothelium-dependent and -independent relaxations in rat perfused mesenteric arterial bed

To investigate the influence of HK-008 on endothelium-dependent and -independent relaxations, we performed a series of experiments in which either ACh $\left(10^{-10}\right.$ to $\left.10^{-5} \mathrm{M}\right)$ or SNP $\left(10^{-9}\right.$ to $\left.10^{-5} \mathrm{M}\right)$ was added cumulatively to perfused mesenteric arterial beds preconstricted by methoxamine $\left(4 \times 10^{-6}\right.$ to $\left.3 \times 10^{-5} \mathrm{M}\right)$. As shown in Fig. 4 , HK-008 $\left(10^{-5} \mathrm{M}\right)$ significantly enhanced the ACh-induced relaxation, but did not alter that induced by SNP (Fig. 4B). The HK008-induced augmentation of the ACh-induced relaxation was significantly inhibited by $10^{-5} \mathrm{M}$ indomethacin, an inhibitor of cyclooxygenase (COX) (Fig. 5). 

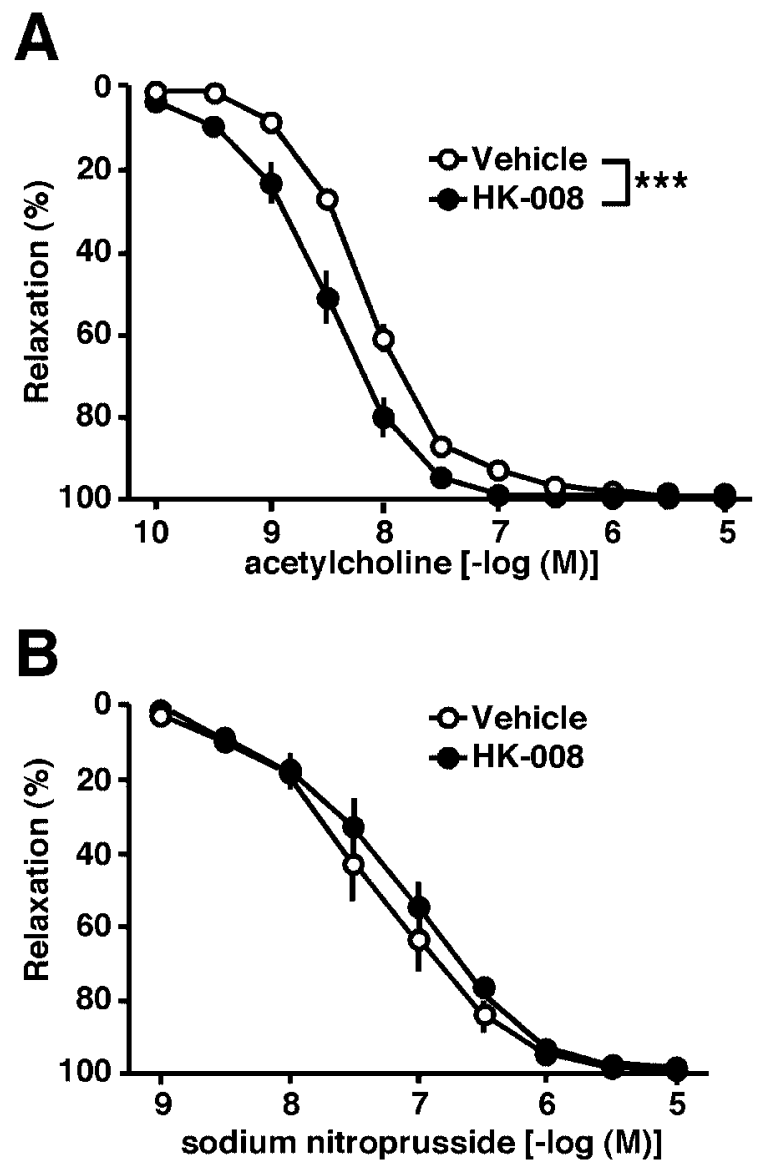

Fig. 4. Effects of HK-008 on the concentration-response curves for acetylcholine- (A) and sodium nitroprusside- $(\mathrm{B})$ induced vasodilatation of methoxamine $\left(4 \times 10^{-6}\right.$ to $3 \times 10^{-5}$ M)-preconstricted mesenteric arterial beds from rats. In each experiment, HK-008 (10 $\mu \mathrm{M})$ was applied 30 min before methoxamine application and was present thereafter. Details are given in Methods. Each data-point represents the mean \pm S.E.M. from 5 experiments; the S.E.M. is included only when it exceeds the dimension of the symbol used. ${ }^{* * *} P<0.001$.

Effects of xanthine oxidase/hypoxanthine on ACh-induced relaxation in rat perfused mesenteric arterial bed

It has been reported (Cai and Harrison, 2000; Kobayashi et al., 2005; Matsumoto et al., 2004c, 2006b; Pieper, 1998) that oxidative stress causes endothelial dysfunction in several vascular beds. To determine whether our synthesized compound might influence the oxidative stress-induced modification of endothelium-dependent relaxation, we examined the effects of HK-008 on ACh-induced relaxation in the perfused mesenteric arterial bed with xanthine oxidase/hypoxanthine present to generate superoxide anions. This superoxide-generating treatment significantly decreased the ACh-induced relaxation (Fig. 6). Interestingly, this impaired relaxation was greatly improved by HK-008 (10-5 M) (Fig. 6). 


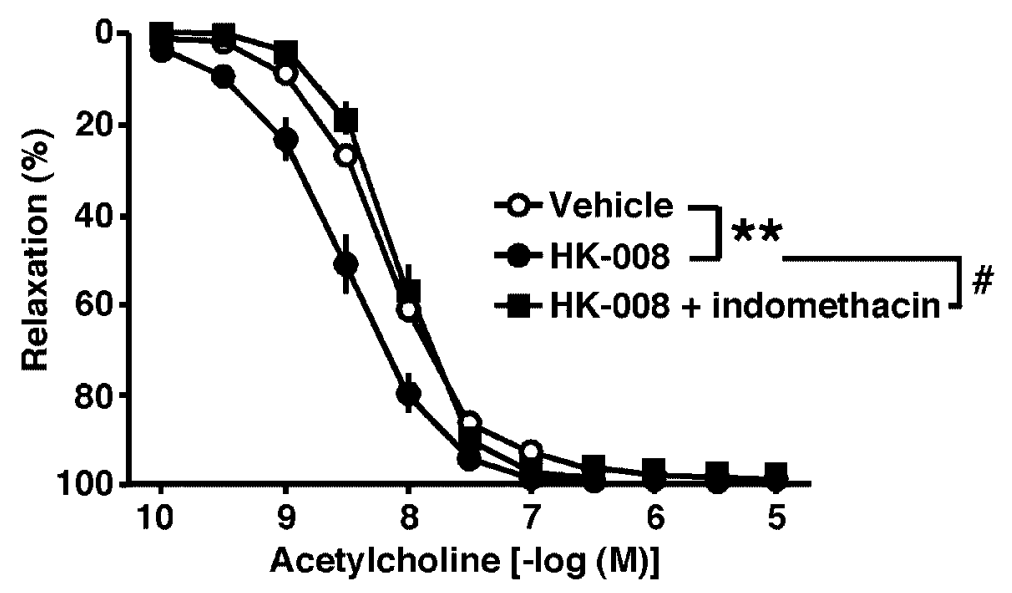

Fig. 5. Effects of HK-008 plus indomethacin on the concentration-response curves for acetylcholine-induced vasodilatation of methoxamine $\left(4 \times 10^{-6}\right.$ to $\left.3 \times 10^{-5} \mathrm{M}\right)$ preconstricted mesenteric arterial beds from rats. In each experiment, HK-008 (10 $\mu \mathrm{M})$ and indomethacin $(10 \mu \mathrm{M})$ was applied 30 min before methoxamine application and was present thereafter. Details are given in Methods. Each data-point represents the mean \pm S.E.M. from 5 experiments; the S.E.M. is included only when it exceeds the dimension of the symbol used. ${ }^{* \star} P<0.01$ vs. vehicle-treated group. ${ }^{\#} P<0.05, v s$. HK-008 plus indomethacin-treated group.

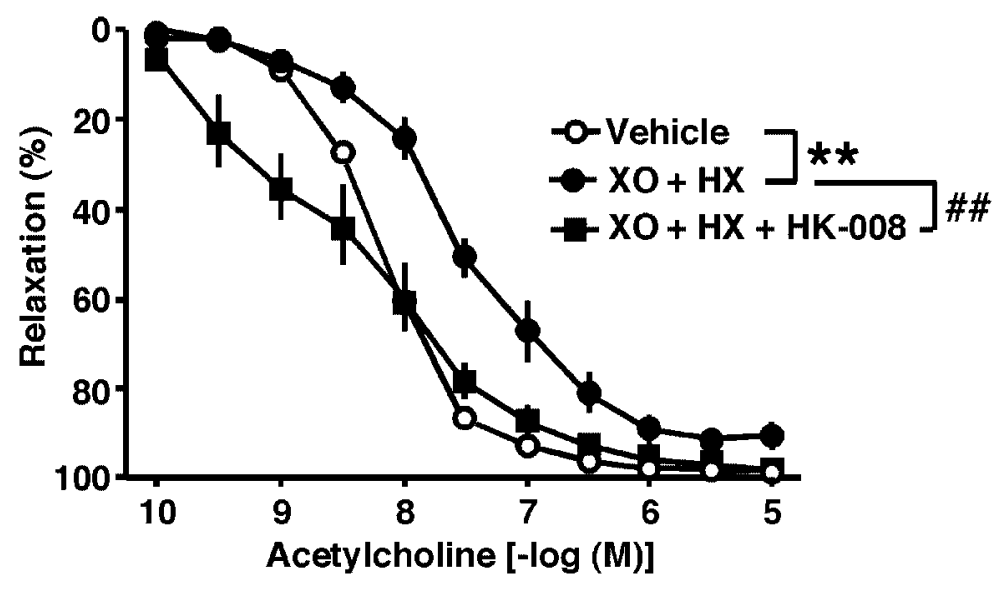

Fig. 6. Effects of xanthine oxidase $(\mathrm{XO} ; 0.1 \mathrm{U} / \mathrm{ml}) /$ hypoxanthine $(\mathrm{HX} ; 10 \mu \mathrm{M})$ and xanthine oxidase $(0.1 \mathrm{U} / \mathrm{ml}) /$ hypoxanthine $(10 \mu \mathrm{M})$ plus HK-008 on the concentrationresponse curves for acetylcholine-induced vasodilatation of methoxamine $\left(4 \times 10^{-6}\right.$ to 3 $\times 10^{-5} \mathrm{M}$ )-preconstricted mesenteric arterial beds from rats. In each experiment, xanthine oxidase $(0.1 \mathrm{U} / \mathrm{ml}) /$ hypoxanthine $(10 \mu \mathrm{M})$ and HK-008 $(10 \mu \mathrm{M})$ was applied $30 \mathrm{~min}$ before methoxamine application and was present thereafter. Details are given in Methods. Each data-point represents the mean \pm S.E.M. from 5 experiments; the S.E.M. is included only when it exceeds the dimension of the symbol used. ${ }^{\star \star} P<0.01$ vs. vehicle-treated group. ${ }^{\#} P<0.01$, vs. XO/HX plus HK-008-treated group. 


\section{Discussion}

In this study, we investigated the effect of the anthocyanidin derivative HK-008 on AChinduced relaxation in the rat perfused mesenteric arterial bed. The major conclusions to be drawn from this study are first that the relaxation induced in this bed by $\mathrm{ACh}$ is markedly enhanced by HK-008 and second that the main mechanism underlying this enhancement seems to involve an elevated production of prostanoids and increased antioxidant activity.

Our first finding was to note a glucose-lowering effect of HK-008, as well as of the SU drug glibenclamide, in the intraperitoneal glucose tolerance test. Published reports indicate that consumption of fruits and vegetables, especially those rich in polyphenols, decreases the incidence of type 2 diabetes (Anderson and Polansky, 2002; Landrault et al., 2003; Anderson et $a l ., 2004)$. Moreover, it is known that dietary antioxidants protect pancreatic $\beta$-cells against glucose-induced oxidative stress. Anthocyanins are abundant in fruits, vegetables, and processed food products such as wine, cider, and tea. However, little is known of their ability to reduce or prevent diabetes. Our results suggest that the synthesized anthocyanidin derivative HK-008 is an insulin secretagogue. Indeed, Jayaprakasam et al. (2005) recently reported that anthocyanins and anthocyanidins induce insulin secretion by pancreatic $\beta$-cells, although the cellular mechanism remains unknown. Glibenclamide binds to SU receptors (SUR) on the $\beta$-cell plasma membrane, closes the $\mathrm{K}_{\mathrm{ATP}}$ channel, and thereby enhances glucose-stimulated insulin secretion (Schmid-Antomarchi et al., 1987; Boyd, 1988). SURs are also present on vascular smooth muscle, where they mediate action potential shortening during ischemia and the regulation of vascular tone (Nichols and Lederer, 1991; Quayle et al., 1997). In the present study, pinacidil induced dose-dependent relaxation in rat aortic strips, and this relaxation was markedly inhibited by glibenclamide. HK-008 also caused a significant sift to the right in the dose-dependent relaxation curve for pinacidil (Fig. 3). Thus, these results suggest that the glucose-lowering effect of HK-008 may be attributable to an inhibition of $\mathrm{K}_{\mathrm{ATP}}$ channel activity.

Endothelial cells regulate vascular tone by releasing potent vasoconstrictors (such as endothelin-1 and $\mathrm{TXA}_{2}$ ) and vasodilators (such as prostacyclin, nitric oxide, and endotheliumderived hyperpolarizing factor) (Yanagisawa et al., 1988; Triggle et al., 2003; Tanaka et al., 2004; Kobayashi et al., 2005a; Matsumoto et al., 2006a). Alterations in the production and effects of these endothelial-cell products are at least partly responsible for the abnormal modulation of vascular tone that occurs in certain disease states (Kamata et al., 1989; Cohen, 1995; De Vriese et al., 2000; Matsumoto et al., 2003a,b, 2004e; Sekiguchi et al., 2004). Interestingly, we found here that ACh-induced relaxation was enhanced by HK-008 treatment in the rat mesenteric arterial bed, and that this augmentation was significantly reversed by indomethacin treatment. Moreover, HK-008 proved able to prevent the impairment of the ACh-induced relaxation caused by exposure to oxidative stress (treatment with $\mathrm{XO} / \mathrm{HX}$ ). These results suggest that the compound HK-008 increases endothelium-induced relaxation via a suppressive effect on oxidative stress or by modifying prostanoids signaling. This is consistent with the previous findings that antioxidants (e.g., vitamin E) and polyphenols increase the production of vasodilator prostanoids and thereby protect endothelial cells (Schramm et al., 2001; Stoclet et al., 2004; Wu et al., 2004, 2005). 
Although HK-008 possess the activity of $\mathrm{K}_{\mathrm{ATP}}$ channel inhibition, it should be noted that there is limited evidence that functional $\mathrm{K}_{\mathrm{ATP}}$ channels in vascular smooth muscle cells regulate the vascular tone (Yokoshiki et al., 1998). The membrane potential of vascular smooth muscle cells lies positive to the equilibrium potential of $\mathrm{K}^{+}$, such that opening of $\mathrm{K}_{\text {ATP }}$ channels will hyperpolarize the cell membrane and elicit relaxation. In contrast, closing the channel with a blocker, like glibenclamide, should increase vascular tone. A report in the rabbit vertebral artery showed that glibenclamide depolarized the vascular smooth muscle cell membrane and potentiated the histamine-induced contractions (Nagao et al., 1996). Similarly, in another study in dogs, glibenclamide decreased the coronary blood flow (Narishige et al., 1993). Moreover, Pfister et al. (2004) demonstrated that $\mathrm{K}_{\mathrm{ATP}}$ channels are not involved in the regulation of vascular tone in the bovine coronary artery or the rabbit aorta, because glibenclamide has no effect on resting tone. In the present study, HK-008 also had not effect on resting tone (data not shown). Thus, we suggest that the altered ACh-induced relaxation by HK-008 may be attributed to the inhibition of $\mathrm{K}_{\mathrm{ATP}}$ channel activity. On the other hand, several reports suggested that the increased oxidative stress leads to the alteration of prostanoids signaling. Inactivation of prostacyclin synthase (PGIS) due to nitration results in accumulation of $\mathrm{TXA}_{2} / \mathrm{PGH}_{2}$ (Schmidt $e t$ $a l ., 2003)$. Endothelial cells exposed to high glucose or to inflammatory mediators generate reactive oxygen species (ROS) or $\mathrm{ONOO}^{-}$that inactivate PGIS, result in accumulation of $\mathrm{TXA}_{2}$ / $\mathrm{PGH}_{2}$ (Zou et al., 2002; Cosentino et al., 2003), and lead to agonist-induced vasoconstriction (Bachschmid et al., 2003). Alternatively, ROS or lipid hydroperoxides could lead to activation of one or the other isoform of COX which would also result in increased levels of the vasoconstrictive intermediates (Davidge, 2001). Taken together, we speculate that the increased ACh-induced endothelium-dependent relaxation was mediated by the antioxidant activity and/or modulating prostanoids signaling rather than the inhibition of $\mathrm{K}_{\mathrm{ATP}}$ channel activity. Thus, the HK-008 compound has independent activities such as the inhibition of $\mathrm{K}_{\mathrm{ATP}}$ channel activity and the enhanced effect of endothelium-dependent relaxation.

There is no question that the SUs are very effective and important agents for the reduction of glucose levels in patients with type 2 diabetes. Indeed, they have been the mainstay of oral therapy for decades, and despite the prevalent use of terms such as "SU-failure", SUs have been effective at lowering fasting plasma glucose for many years. Actually, the steadily increasing fasting plasma glucose level seen over time in SU-treated patients does not reflect "failure" of the agent, rather it reflects progression of disease, and it is seen with other therapeutic interventions too (Turner et al., 1999). Despite its efficacy, there are several drawbacks or limitations to SU therapy. Because the insulinotropic actions of SUs are only slowly reversed, hypoglycemia is a frequent side effect of particular concern in elderly patients. Second, SUs stimulate insulin secretion and raise insulin levels throughout the day; in other words, they do not specifically reduce mealtime glucose excursions. Chronic stimulation of insulin secretion, especially with an agent that restrains nutrient-stimulated proinsulin biosynthesis, can lead to $\beta$ cell degranulation and may accelerate $\beta$-cell failure. In addition, chronic hyperinsulinemia itself may have detrimental effects, including an exacerbation of insulin resistance, a propensity to cause weight gain, and possibly an acceleration or worsening of atherosclerosis - already major problems in patients with type 2 diabetes. Finally, Meinert et al. (1970) reported many years 
ago that SUs may actually increase risk of cardiovascular mortality. Thus, there are many reasons to look beyond SUs for agents to stimulate insulin release in a more physiologic manner, and a role may be found for dietary constituents that can regulate blood glucose levels and/or induce insulin production by pancreatic $\beta$-cells.

In conclusion, our results suggest that HK-008 possesses anti-diabetic and antioxidant activities, and is potent at increasing endothelium-dependent relaxation. Since type 2 diabetes entails morphological and functional changes in the micro- and macrocirculation (De Vriese $e t$ al., 2000; Kobayashi et al., 2004a, 2005; Triggle et al., 2003), this compound may be useful for the treatment of type 2 diabetes and the associated vascular complications. However, in vivo studies and clinical evaluation of this compound need be carried out to validate and extend our in vitro results. Since anthocyanidins and anthocyanins are not toxic to humans, evaluation of their clinical efficacy for potential application to the prevention and treatment of type 2 diabetes is a matter of some importance.

\section{Acknowledgments}

This study was supported in part by the Ministry of Education, Culture, Sports, Science and Technology, Japan and by the Mutual Aid Cooperation for Private Schools of Japan.

\section{References}

Anderson, R.A., Broadhurst, C.L., Polansky, M.M., Schmidt, W.F., Khan, A., Flanagan, V.P., Schoene, N.W. and Graves, D.J. (2004). Isolation and characterization of polyphenol type-A polymers from cinnamon with insulin-like biological activity. J. Agric. Food Chem. 52: 65-70.

Anderson, R.A. and Polansky, M.M. (2002). Tea enhances insulin activity. J. Agric. Food Chem. 50: 71827186.

Bachschmid, M., Thurau, S., Zou, M.H. and Ullrich, V. (2003). Endothelial cell activation by endotoxin involves superoxide/NO-mediated nitration of prostacyclin synthase and thromboxane receptor stimulation. FASEB. J. 17: 914-916.

Blakely, S., Herbert, A., Collins, M., Jenkins, M., Mitchell, G., Grundel, E., O’Neill, K.R. and Khachik, F. (2003). Lutein interacts with ascorbic acid more frequently than with alpha-tocopherol to alter biomarkers of oxidative stress in female zucker obese rats. J. Nutr. 133: 2838-2844.

Boyd, A.E. 3rd (1988). Sulfonylurea receptors, ion channels, and fruit flies. Diabetes 37: 847-850.

Cai, H. and Harrison, D.G. (2000). Endothelial dysfunction in cardiovascular diseases: the role of oxidant stress. Circ. Res. 87: 840-844.

Cohen, R.A. (1995). The role of nitric oxide and other endothelium-derived vasoactive substances in vascular disease. Prog. Cardiovasc. Dis. 38: 105-128.

Cosentino, F., Eto, M., De Paolis, P, van der Loo, B., Bachschmid, M., Ullrich, V., Kouroedov, A., Delli Gatti, C., Joch, H., Volpe, M. and Luscher, T.F. (2003). High glucose causes upregulation of cyclooxygenase-2 and alters prostanoid profile in human endothelial cells: role of protein kinase C and reactive oxygen species. Circulation 107: 1017-1023.

Davidge, S.T. (2001). Prostaglandin H synthase and vascular function. Circ. Res. 89: 650-660.

De Vriese, A.S., Verbeuren, T.J., Van de Voorde, J., Lameire, N.H. and Vanhoutte, P.M. (2000). Endothelial dysfunction in diabetes. Br. J. Pharmacol. 130: 963-974.

Duthie, G.G., Duthie, S.J. and Kyle, J.A.M. (2000). Plant polyphenols in cancer and heart disease: 
implications as nutritional antioxidants. Nutr. Res. Rev. 13: 79-106.

Eckel, R.H., Wassef, M., Chait, A., Sobel, B., Barrett, E., King, G., Lopes-Virella, M., Reusch, J., Ruderman, N., Steiner, G. and Vlassara, H. (2002). Prevention Conference VI: Diabetes and Cardiovascular Disease: Writing Group II: pathogenesis of atherosclerosis in diabetes. Circulation 105: e138-e143.

Espin, J.C., Soler-Rivas, C., Wichers, H.J. and Garcia-Viguera, C. (2000). Anthocyanin-based natural colorants: a new source of antiradical activity for foodstuff. J. Agric. Food Chem. 48: 1588-1592.

Henquin, J.C. (2000). Triggering and amplifying pathway of regulation of insulin secretion by glucose. Diabetes 49: 1751-1760.

Jayaprakasam, B., Strasburg, G.A. and Nair, M.G. (2004). Potent lipid peroxidation inhibitors from Withania somnifera. Tetrahedron 60: 3109-3121.

Kamata, K. and Makino, A. (1997). A comparative study on the rat aorta and mesenteric arterial bed of the possible role of nitric oxide in the desensitization of the vasoconstrictor response to an alpha 1-adrenoceptor agonist. Br. J. Pharmacol. 120: 1221-1228.

Kamata, K., Miyata, N. and Kasuya, Y. (1989). Impairment of endothelium-dependent relaxation and changes in levels of cyclic GMP in aorta from streptozotocin-induced diabetic rats. Br. J. Pharmacol. 97: 614-618.

Kang, S.Y., Seeram, N.P., Nair, M.G. and Bourquin, L.D. (2003). Tart cherry anthocyanins inhibit tumor development in Apc(Min) mice and reduce proliferation of human colon cancer cells. Cancer Lett. 194: 13-19.

Kanie, N., Matsumoto, T., Kobayashi, T. and Kamata, K. (2003). Relationship between peroxisome proliferators-activated receptors (PPAR alpha and PPAR gamma) and endothelium-dependent relaxaton in streptozotocin-induced diabetic rats. Br. J. Pharmacol. 140: 23-32.

Kobayashi, T., Matsumoto, T. and Kamata, K. (2000). Mechanisms underlying the chronic pravastatin treatment-induced improvement in the impaired endothelium-dependent aortic relaxation seen in streptozotocin-induced diabetic rats. Br. J. Pharmacol. 131: 231-238.

Kobayashi, T., Matsumoto, T. and Kamata, K. (2005a). IGF-I-induced enhancement of contractile response in organ-cultured aortae from diabetic rats is mediated by sustained thromboxane A2 release from endothelial cells. J. Endocrinol. 186: 367-376.

Kobayashi, T., Matsumoto, T. and Kamata, K. (2005b). The PI3-K/Akt pathway: roles related to alterations in vasomotor responses in diabetic models. J. Smooth Muscle Res. 41: 283-302.

Kobayashi, T., Matsumoto, T., Ooishi, K. and Kamata, K. (2004a). Differential expression of $\alpha_{2 D^{-}}$ adrenoceptor and eNOS in aortas from early and later stages of diabetes in Goto-Kakizaki rats. Am. J. Physiol. Heart Circ. Physiol. 287: H135-H143.

Kobayashi, T., Taguchi, K., Yasuhiro, T., Matsumoto, T. and Kamata, K. (2004b). Impairment of PI3-K/ Akt pathway underlies attenuated endothelial function in aorta of type 2 diabetic mouse model. Hypertension 44: 956-962.

Landrault, N., Poucheret, P., Azay, J., Krosniak, M., Gasc, F., Jenin, C., Cros, G. and Teissedre, P.L. (2003). Effect of a polyphenols-enriched chardonnay white wine in diabetic rats. J. Agric. Food Chem. 51: 311-318.

Makino, A. and Kamata, K. (1998). Possible modulation by endothelin-1, nitric oxide, prostaglandin I2 and thromboxane $\mathrm{A} 2$ of vasoconstriction induced by an alpha-agonist in mesenteric arterial bed from diabetic rats. Diabetologia 41: 1410-1418.

Makino, A. and Kamata, K. (2002). Effects of chronic administration of L-arginine on vasoactive responses induced by endothelin-1 and its plasma level in streptozotocin-induced diabetic rats. J. Smooth Muscle Res. 38: 101-115.

Makino, A., Ohuchi, K. and Kamata, K. (2000). Mechanisms underlying the attenuation of endotheliumdependent vasodilatation in the mesenteric arterial bed of the streptozotocin-induced diabetic rat. Br. J. Pharmacol. 130: 549-556. 
Matsumoto, T., Kobayashi, T. and Kamata, K. (2003a). Alterations in EDHF-type relaxation and phosphodiesterase activity in mesenteric arteries from diabetic rats. Am. J. Physiol. Heart Circ. Physiol. 285: H283-H291.

Matsumoto, T., Kobayashi, T. and Kamata, K. (2003b). Phosphodiesterases in the vascular system. J. Smooth Muscle Res. 39: 67-86.

Matsumoto, T., Kobayashi, T. and Kamata, K (2006a). A therapeutic target for microvascular complications in diabetes: endothelium-derived hyperpolarizing factor. Curr. Cardiol. Rev. 2: 185-191.

Matsumoto, T., Kobayashi, T., Kikuchi, T., Honda, T. and Kamata, K. (2005). Effects of dual-action genistein derivatives on relaxation in rat aorta. J. Smooth Muscle Res. 41: 23-33.

Matsumoto, T., Miyamori, K., Kobayashi, T. and Kamata, K (2006b). Specific impairment of endothelium-derived hyperpolarizing factor-type relaxation in mesenteric arteries from streptozotocin-induced diabetic mice. Vascul. Pharmacol. 44: 450-460.

Matsumoto, T., Oda, S.I., Kobayashi, T. and Kamata, K. (2004a). Flow-induced endothelium-dependent vasoreactivity in rat mesenteric arterial bed. J. Smooth Muscle Res. 40: 1-14.

Matsumoto, T., Sato, A., Suenaga, H., Kobayashi, T. and Kamata, K. (2004b). Modulations of shear stress-induced contractile responses and agonist-induced vasodilation in hypercholesterolemic rats. Atherosclerosis 175: 31-38.

Matsumoto, T., Yoshiyama, S., Wakabayashi, K., Kobayashi, T. and Kamata, K. (2004c). Effects of chronic insulin on endothelial dysfunction of basilar arteries from established streptozotocindiabetic rats. Eur. J. Pharmacol. 504: 119-127.

Matsumoto, T., Wakabayashi, K., Kobayashi, T. and Kamata, K. (2004d). Alterations in vascular endothelial function in the aorta and mesenteric artery in type II diabetic rats. Can. J. Physiol. Pharmacol. 82: 175-182.

Matsumoto, T., Wakabayashi, K., Kobayashi, T. and Kamata, K. (2004e). Diabetes-related changes in cAMP-dependent protein kinase activity and decrease in relaxation response in rat mesenteric artery. Am. J. Physiol. Heart Circ. Physiol. 287: H1064-H1071.

Meinert, C.L., Knatterud, G.L., Prout, T.E. and Klimt, C.R. (1970). A study of the effects of hypoglycemic agents on vascular complications in patients with adult-onset diabetes. II. Mortality results. Diabetes 19: 789-830.

Nagao, T., Ibayashi, S., Sadoshima, S., Fujii, K., Fujii, K., Ohya, Y. and Fujishima, M. (1996). Distribution and physiological roles of ATP-sensitive- $\mathrm{K}^{+}$channels in the vertebrobasilar system of the rabbit. Circ. Res. 78: 238-243.

Narishige, T., Egashira, K., Akatsuka, Y., Katsuda, Y., Numaguchi, K., Sakata, M. and Takeshita, A. (1993). Glibenclamide, a putative ATP-sensitive-K ${ }^{+}$channel blocker, inhibits coronary autoregulation in anesthetized dogs. Circ. Res. 73: 771-776.

Nichols, C.G. and Lederer, W.J. (1991). Adenosine triphosphate-sensitive potassium channels in the cardiovascular system. Am. J. Physiol. 261: H1675-H1686.

Pfeiffer, A.F.H. (2003). Oral hypoglycemic agents: Sulfonylureas and meglitinides. In: Text Book of Type-2 Diabetes, ed. by B.J. Goldstein and D. Muller-Wieland, Martin Dunitz Ltd., London, pp. $77-85$.

Pfister, S.L., Pratt, P.E., Kurian, J. and Campbell, W.B. (2004). Glibenclamide inhibits thromboxanemediated vasoconstriction by thromboxane receptor blockade. Vascul. Pharmacol. 40: 285-292.

Pieper, G.M. (1998). Review of alterations in endothelial nitric oxide production in diabetes: protective role of arginine on endothelial dysfunction. Hypertension 31: 1047-1060.

Quayle, J.M., Nelson, M.T. and Standen, N.B. (1997). ATP-sensitive and inwardly rectifying potassium channels in smooth muscle. Physiol. Rev. 77: 1165-1232.

Schmid-Antomarchi, H., de Weille, J., Fosset, M. and Lazdunski, M. (1987). The antidiabetic sulfonylurea glibenclamide is a potent blecker of the ATP-modulated $\mathrm{K}^{+}$channel in insulin 
secreting cells. Biochem. Biophys. Res. Commun. 15: 21-25.

Schmidt, P., Youhnovski, N., Daiber, A., Balan, A., Arsic, M., Bachschmid, M., Przybylski, M. and Ullrich, V. (2003). Specific nitration at tyrosine 430 revealed by high resolution mass spectrometry as basis for redox regulation of bovine prostacyclin synthase. J. Biol. Chem. 278: 12813-12819.

Schramm, D.D., Wang, J.F., Holt, R.R., Ensunsa, J.L., Gonsalves, J.L., Lazarus, S.A., Schmitz, H.H., German, J.B. and Keen, C.L. (2001). Chocolate procyanidins decrease the leukotrieneprostacyclin ratio in humans and human aortic endothelial cells. Am. J. Clin. Nutr. 73: 36-40.

Sekiguchi, F., Yanamoto, A. and Sunano, S. (2004). Superoxide dismutase reduces the impairment of endothelium-dependent relaxation in the spontaneously hypertensive rat. J. Smooth Muscle Res. 40: 65-74.

Stoclet, J.C., Chataigneau, T., Ndiaye, M., Oak, M.H., El Bedoui, J., Chataigneau, M. and Schini-Kerth, V.B. (2004). Vascular protection by dietary polyphenols. Eur. J. Pharmacol. 500: 299-313.

Strack, D. and Wray, V. (1993). The anthocyanins. In: The flavonoids: advances in research since 1986, ed. by J.B. Harborne, Chapman and Hall, London, pp. 1-19.

Tanaka, Y., Koike, K. and Toro, L. (2004). MaxiK channel roles in blood vessel relaxations induced by endothelium-derived relaxing factors and their molecular mechanisms. J. Smooth Muscle Res. 40: $125-153$.

Triggle, C.R., Hollenberg, M., Anderson, T.J., Ding, H., Jiang, Y., Ceroni, L., Wiehler, W.B., Ng, E.S., Ellis, A., Andrews, K., McGuire, J.J. and Pannirselvam, M. (2003). The endothelium in health and disease-a target for therapeutic intervention. J. Smooth Muscle Res. 39: 249-267.

Tsuda, T., Horio, F., Uchida, K., Aoki, H. and Osawa, T. (2003). Dietary cyaniding 3-O-beta-D-glucosiderich purple corn color prevents obesity and ameliorates hyperglycemia in mice. J. Nutr. 133: 2125-2130.

Turner, R.C., Cull, C.A., Frighi, V. and Holman, R.R. (1999). Glycemic control with diet, sulfonylurea, metformin, or insulin in patients with type 2 diabetes mellitus: progressive requirement for multiple therapies (UKPDS 49). UK Prospective Diabetes Study (UKPDS) Group. JAMA. 281: 2005-2012.

Van Velden, D.P., Mansvelt, E.P., Fourie, E., Rossouw, M. and Marais, A.D. (2002). The cardioprotective effect of wine on human blood chemistry. Ann. N. Y. Acad. Sci. 957: 337-340.

Wang, H., Gao, G. and Prior, R.L. (1997). The oxygen radical absorbing capacity of anthocyanins. $J$. Agric. Food Chem. 45: 304-309.

Wu, D., Liu, L., Meydani, M. and Meydani, S.N. (2004). Effect of vitamin E on prostacyclin (PGI2) and prostaglandin (PG) E2 production by human aorta endothelial cells: mechanism of action. Ann. N.Y. Acad. Sci. 1031: 425-427.

Wu, D., Liu, L., Meydani, M. and Meydani, S.N. (2005). Vitamin E increases production of vasodilator prostanoids in human aortic endothelial cells through opposing effects on cyclooxygenase-2 and phospholipase A2. J. Nutr. 135: 1847-1853.

Yanagisawa, M., Kurihara, H., Kimura, S., Tomobe, Y., Kobayashi, M., Mitsui, Y., Yazaki, Y., Goto, K. and Masaki, T. (1988). A novel potent vasoconstrictor peptide produced by vascular endothelial cells. Nature 332: 411-415.

Yokoshiki, H., Sunagawa, M., Seki, T. and Sperelakis, N. (1998). ATP-sensitive $\mathrm{K}^{+}$channels in pancreatic, cardiac, and vascular smooth muscle cells. Am. J. Physiol. 274: C25-C37.

Zou, M.H., Shi, C. and Cohen, R.A. (2002). High glucose via peroxynitrite cause tyrosine nitration and inactivation of prostacyclin synthase that is associated with thromboxane/prostaglandin $\mathrm{H}(2)$ receptor-mediated apoptosis and adhesion molecule expression in cultured human aortic endothelial cells. Diabetes 51: 198-203. 